Original article (short paper)

\title{
Relationship between resting heart rate and anthropometric, metabolic and hemodynamic parameters in the elderly aged 80 years and over
}

\author{
Fabrício E. Rossi \\ Universidade Estadual Paulista “Júlio de Mesquita Filho”, Rio Claro, SP, Brasil \\ Ana Laura Ricci-Vitor \\ Universidade Federal de São Paulo, São Paulo, SP, Brasil \\ Igor C. Gomes \\ Universidade de São Paulo, São Paulo, SP, Brasil. \\ Vanessa R. Santos \\ Universidade Estadual Paulista "Júlio de Mesquita Filho", Rio Claro, SP, Brasil \\ João Paulo J. Sabino \\ Luiz Guilherme S. Branco \\ Universidade de São Paulo, Ribeirão Preto, SP, Brazil \\ Diego G. D. Christofaro \\ Luiz Carlos M. Vanderlei \\ Ismael F. Freitas Junior \\ Universidade Estadual Paulista “Júlio de Mesquita Filho”, Presidente Prudente, SP, Brasil.
}

\begin{abstract}
This study examined the relationship between resting heart rate (RHRr) and anthropometric, metabolic and hemodynamic parameters in subjects aged 80 years and over. One hundred thirteen individuals were divided into two groups (RHR: $<66$ beats/min and $\geq 66$ beats/min). Anthropometric parameters (weight, height, body mass index and waist circumference (WC) were measured. Hemodynamic parameters (systolic (SBP) and diastolic (DBP) pressure) were measured and pulse pressures (PP) were obtained. Metabolic parameters were fasting blood glucose, triglycerides and total cholesterol. In elderly aged 80 and over, RHR influenced the changes observed in DBP, PP and triglycerides. Additionally, subjects with RHR $\geq 66$ beats/min had higher DBP, glucose, total cholesterol and lower PP as compared with elderly with RHR $<66$ beats/min. Men demonstrated greater weight, height, and WC than women while women had higher percentage of body fat, trunk fat, and higher total cholesterol. Thus, subjects with 80 years old and over who present RHR $\geq 66$ have higher DBP and lower PP and heart rate variability compared with the elderly with RHR $<66$.
\end{abstract}

Keywords: heart rate, glucose, arterial pressure.

\section{Introduction}

The life expectancy of the population, especially the elderly, has increased. It is estimated that by 2050 , one in five individuals will be elderly (Hashmi et al., 2014). Associated with aging, an increase in the prevalence of cardiovascular and cerebrovascular diseases is also found that is considered the leading cause of death in this population (Santana et al., 2013).

The identification of risk factors is of great importance regarding predictors of mortality (Benetos, Rudnichi,
Thomas, Safar, \& Guize, 1999), as well as enabling the implementation of intervention strategies for the prevention of cardiovascular disease (Girotto, Andrade, Cabrera, \& Ridão, 2009), and its complications (Nogueira, Ribeiro, \& Cruz, 2009).

In this context, resting heart rate (RHR) has been widely used, as a non-invasive, easily applied and low cost approach, in studies to identify cardiovascular risk factors (Benetos, et al., 1999; Park, Lee, Shim, Lee, Jung, \& Lee, 2010; Freitas Jr et al.,2012; Kowalski et al.,2012). In addition, RHR is currently considered as an independent cardiovascular risk 
factor (Palatini, 2009). Studies with subjects of different age groups found a positive relationship between RHR and total cholesterol, triglycerides, dyslipidemia (Park et al., 2010), arterial stiffness (Benetos et al.,1999) and disorders of the carbohydrate metabolism (Kowalski et al., 2012), as well as an increase in cardiovascular diseases (Cooney, Vartiainen, Laatikainen, Juolevi, Dudina, \& Graham, 2010). However, in the elderly aged 80 years and over, it is not yet clear whether the relationship between RHR and anthropometric, metabolic and hemodynamic parameters is similar to that in individuals of other age groups.

Thus, we hypothesized that elderly subjects aged 80 years and over who presented lower RHR values would have better health components (hemodynamic, anthropometric and metabolic) compared to the elderly with higher RHRs. Thus, the objective of this study was to compare the hemodynamic, anthropometric and metabolic parameters with the RHR in elderly subjects aged 80 years and over.

\section{Method}

\section{Participants}

This was a transversal, randomized study, which was conducted from October 2009 to May 2010 in the city of Presidente Prudente, São Paulo, Brazil. The name, address and telephone number of all subjects aged 80 and over were obtained from the Public Health System registers in Presidente Prudente-SP, Brazil. In order to ensure that all individuals who lived in the urban area presented the same chance of being part of the study, a simple randomized draw was conducted and all contacts were made by phone.

The following exclusion criteria were adopted: 1) Bedridden elderly; 2) Living in rural areas; 3) Using pacemakers; 4) Not performing the pre-established evaluations. Thus, the final sample selected for analysis consisted of 113 subjects, 39 men and 74 women.

All study participants were informed about the study procedures and only those who signed the informed consent were included in the sample. All protocols were reviewed and approved by the Ethics Committee of the São Paulo State University (Protocol no. 26/2009).

\section{Procedures}

\section{Hemodynamic parameters}

\section{Resting heart rate}

The RHR assessments were performed individually in a room with an ambient temperature of between 21 and $23^{\circ} \mathrm{C}$ and relative humidity of between 40 and $60 \%$ (Palatini et $a l ., 2006)$. The volunteers were instructed not to consume alcohol and/or stimulant drinks such as coffee and tea for a period of 12 hours prior to the assessment, and any participants who used medications, were requested to suspend them for a period of 12 hours prior the evaluation (Rossi, Ricci-Vitor, Sabino, Vanderlei \& Freitas, 2014).

On the day of data collection, the volunteers were instructed to remain in silence, awake, resting, spontaneously breathing whilst sitting comfortably for five minutes. After the explanation of the procedures for data collection, an elastic strap was positioned around the chest, at the height of the xiphoid process, and a heart rate receiver, Polar S810i (Polar Electro, S810i model, Finland), was placed on the pulse. For the data recording, two samples of 30 seconds duration were taken with a three-minute interval between them and the average of the two recordings was used for analysis. Data were recorded in beats per minute (beats/min).

For classification of individuals with higher or lower RHR, after verifying that the data did not have normal distribution using the Kolmogorov-Smirnov test, and taking into account the lack of cut-off points for this variable, the median values of the total sample were used. Thus, individuals who presented RHR $\geq 66$ beats/min were classified with higher RHR and those who presented RHR $<66$ beats/min were classified with lower RHR.

\section{Arterial pressure}

Prior to the measurement of blood pressure (BP), the participants remained seated at rest for five minutes, following the recommendations of the American Heart Association (Pickering et al., 2005). To measure the BP, an automatic blood pressure monitor (Omron Healthcare brand, Inc., Intellisense, Model HEM 742 INT, Bannockburn, Illinois, USA), previously validated for use in adults (Coleman, Freeman, Steel, \& Shennan, 2005) was used. Two measurements were made with a two-minute interval between them. Thus, the means of systolic blood pressure (SBP) and diastolic blood pressure (DBP) were obtained. Mean blood pressure (MBP) was calculated using the following formula: $\mathrm{MBP}=\mathrm{DBP}+1 / 3$ (SBP $-\mathrm{DBP})$. In addition, pulse pressure $(\mathrm{PP})$ was obtained from the difference between the SBP and DBP (PP = SBP - DBP).

\section{Heart rate variability}

Heart rate variability (HRV) was analyzed in both time and frequency domains. In the time domain HRV was quantified by the average and the standard deviation of the differences between consecutive heart beats. For analysis in the frequency domain, the time series of the pulse intervals were interpolated at $10 \mathrm{~Hz}$ and divided into segments of 512 continuous beats, overlapping by $50 \%$. Each segment was subjected to a Hanning window type and analysis was performed by the Fourier rapid transformer (FFT). The oscillatory components found were quantified into bands of low (LF: $0.04-0.15 \mathrm{~Hz}$ ) and high frequency (HF: $0.15-$ $0.40 \mathrm{~Hz}$ ). This analysis was carried out using the software CardioSeries v. 1.0 (http://sites.google.com/site/cardioseries) 
(Kochiadakis, Kanoupakis, Rombola, A. T., Igoumenidis, N. E., Chlouverakis, G. I., \& Vardas, 1998).

\section{Anthropometric parameters}

\section{Anthropometry and Body Composition}

Height was measured using a fixed stadiometer (Sanny, Brazil), with an accuracy of $0.1 \mathrm{~cm}$ and a maximum length of $2.2 \mathrm{~m}$. The evaluated subjects were barefoot, wearing light clothing and standing at the base of the stadiometer, positioning themselves with their backs to the machine, touching their shoulder blades, buttocks and heels to the equipment's vertical support. The head was positioned in the Frankfurt plane, eyes fixed towards the horizon, allowing the movable part of the stadiometer could be positioned correctly. The body mass measurement was performed using a digital scale (Filizola, Brazil), with an accuracy of $0.1 \mathrm{~kg}$ and a maximum capacity of $180 \mathrm{~kg}$. Participants were barefoot and wearing light clothing so as not to interfere with the measurement. At the time of the measurement, the volunteers were positioned standing immobile without support on the scale platform, facing the researcher (Freitas Jr, 2009).

Waist circumference (WC) was measured around the smallest circumference between the upper edge of the iliac crest and the last rib, using a metal tape (Sanny, Brazil) with a 1 millimeter precision. The cut-offs used were $\geq 88 \mathrm{~cm}$ for women and $\geq 102$ $\mathrm{cm}$ for men (Lean, Han, \& Morrison, 1995).

For the analysis of body composition and body fat distribution the Dual-Energy X-ray Absorptiometry (DXA) scanner version 4.7 (General Electric Healthcare, Lunar DPX-NT; England, UK) technique was used. The examination lasted for approximately 15 minutes. The participants were positioned on the unit in a supine position and remained motionless throughout the examination. This method estimates body composition by dividing the body into three anatomic components: fat free mass, fat mass and bone mineral content. Thus the percentage of body fat $(\% \mathrm{BF})$ and percentage trunk fat $(\% \mathrm{TF})$ were estimated.

The classification of overweight was according WHO (2004) $(\mathrm{BMI}=>24.9)$ and waist circumference $(102 \mathrm{~cm}$ to men and $88 \mathrm{~cm}$ for women) (Lean, Han, Morrison, 1995). The metabolic syndrome classification was according the International Diabetes Federation (IDF): 1- concentration of triglycerides $\geq 150 \mathrm{mg} / \mathrm{dl}$; 2- blood pressure systolic $\geq 130 \mathrm{mmHg}$ or diastolic blood pressure $\geq 85 \mathrm{mmHg}$; 3 - fasting plasma glucose concentration $\geq 100 \mathrm{mg} / \mathrm{dl}$.

\section{Metabolic Parameters}

Blood collection was after 12 hrs of overnight fasting. Blood samples were collected in vacuum tubes without anticoagulant separating gel; after collection, the blood was centrifuged for 10 minutes at 3,000 rpm to separate the serum from the other blood components, and the serum was used for analysis.
For determination of glucose (GLU), triglycerides (TG) and, total cholesterol (TC) an enzymatic colorimetric kit was used and processed in an Autohumalyzer A5 (Human, \& Jones, 2004).

\section{Statistical Analysis}

For the statistical treatment, data distribution was checked using the Kolmogorov-Smirnov test and, based on the data set, nonparametric statistics were performed and the data were described as median and interquartile range, according to sex. The Mann-Whitney test was used for comparison of hemodynamic and metabolic variables according to RHR and sex. The Spearman rank correlation (rho) was used to analyze the relationship between RHR and the independent variables (SBP, DBP, PP, TG, $\mathrm{TC}$ and GLU) and linear regression was used with adjust for age, sex, and \% BF. Statistical analysis was performed using the SPSS statistical package version 17.0 (SPSS, Inc. Chicago, IL, USA) software and the level of statistical significance was set at $5 \%$.

\section{Results}

We assessed 113 individuals over 80 years old. The total prevalence of overweight was $(n=69,61.1 \%)$, central obesity $(n=$ $49,40.2 \%)$, hypertension $(n=99,87.6 \%)$, hyperglycaemia $(n=$ $29,25.7 \%)$, hyper triglycerides $(n=34,30.1 \%)$. Additionally, Figure 1 shows the prevalence of RHR in the group of elderly patients, according to gender. It can be observed that $40.5 \%$ of the women had RHR values equal to or greater than 66 beats/ min, while in the men this percentage was $51.3 \%$, equivalent to $44.2 \%$ of the total sample $(\mathrm{p}=0.882)$.

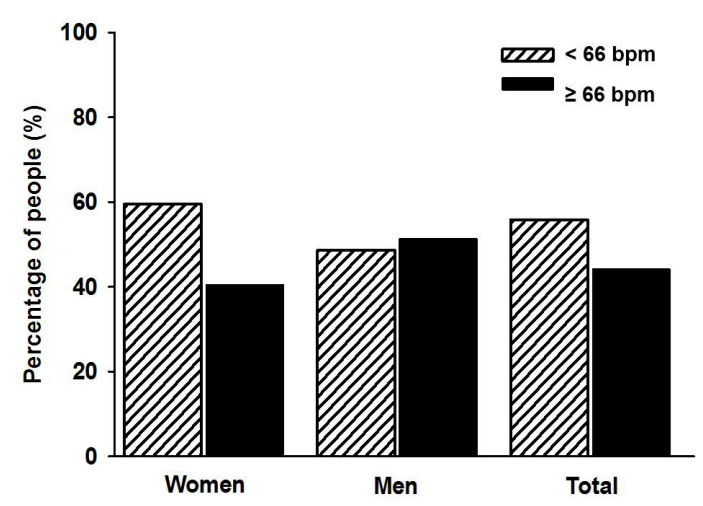

Figure 1. Prevalence of resting heart rate according to gender in elderly aged 80 years and over.

Table 1 presents the sample characteristics with the values presented as median and interquartile range, as well as the comparison between genders. Men had higher values for weight, height and WC compared with women $(\mathrm{p}<0.001)$, whereas the women had higher values for $\mathrm{TC}, \% \mathrm{BF}$ and $\mathrm{TF} \%(\mathrm{p}<0.001)$. No significant difference was observed in the remaining variables. 
Table 1. Comparison of variables in relation to anthropometric, metabolic, hemodynamic and heart rate variability according to gender in the elderly aged 80 years old and over.

\begin{tabular}{|c|c|c|c|c|c|}
\hline Variable & $\begin{array}{l}\text { Men }(n=39) \\
\text { Median }\end{array}$ & $\begin{array}{c}\text { Percentile } \\
(25-75)\end{array}$ & $\begin{array}{c}\text { Women }(n=74) \\
\text { Median }\end{array}$ & $\begin{array}{c}\text { Percentile } \\
(25-75)\end{array}$ & $p$ \\
\hline Age (years) & 82.80 & $(81.40-84.20)$ & 82.70 & $(81.20-84.80)$ & 0.809 \\
\hline Weight $(\mathrm{Kg}) \$$ & 71.70 & $(63.60-84.60)$ & 56.80 & $(49.60-66.40)$ & 0.00 \\
\hline Height $(\mathrm{cm}) \$$ & 165.50 & $(161.00-169.60)$ & 150.50 & $(145.50-154.00)$ & 0.00 \\
\hline BMI (kg/m2) & 26.30 & $(24.20-30.50)$ & 25.70 & $(22.50-28.10)$ & 0.13 \\
\hline $\mathrm{WC}(\mathrm{cm}) \$$ & 99.60 & $(89.30-108.80)$ & 85.20 & $(79.50-96.90)$ & 0.00 \\
\hline$\%$ BF \$ & 32.00 & $(25.40-35.70)$ & 42.20 & $(34.70-47.70)$ & 0.00 \\
\hline$\% \mathrm{TF} \$$ & 38.30 & $(28.30-42.90)$ & 43.70 & $(35.10-49.40)$ & 0.00 \\
\hline $\mathrm{SBP}(\mathrm{mmHg})$ & 156.00 & $(141.00-171.00)$ & 153.00 & $(140.00-168.00)$ & 0.72 \\
\hline $\mathrm{DBP}(\mathrm{mmHg})$ & 78.00 & $(71.00-87.00)$ & 78.00 & $(68.70-87.00)$ & 0.94 \\
\hline MBP $(\mathrm{mmHg})$ & 105.60 & $(95.30-112.60)$ & 103.30 & $(95.00-114.50)$ & 0.961 \\
\hline RHR (bpm) & 66.00 & $(59.00-76.00)$ & 64.00 & $(57.00-70.20)$ & 0.31 \\
\hline $\mathrm{PP}(\mathrm{mmHg})$ & 72.00 & $(62.00-86.00)$ & 76.00 & $(64.70-87.50)$ & 0.19 \\
\hline $\mathrm{TG}(\mathrm{mg} / \mathrm{dl})$ & 106.00 & $(81.00-153.00)$ & 112.50 & $(94.50-161.20)$ & 0.53 \\
\hline $\mathrm{TC}(\mathrm{mg} / \mathrm{dl}) \$$ & 182.00 & $(156.00-203.00)$ & 212.50 & $(191.50-232.00)$ & 0.00 \\
\hline GLU (mg/dl) & 91.00 & $(86.00-112.00)$ & 90.00 & $(85.00-99.00)$ & 0.38 \\
\hline RR-Mean (ms) \# & 82.80 & $(81.40-84.20)$ & 82.70 & $(81.20-84.80)$ & 0.809 \\
\hline SD \# & 71.70 & $(63.60-84.60)$ & 56.80 & $(49.60-66.40)$ & 0.00 \\
\hline $\operatorname{LF}\left(\mathrm{ms}^{2}\right) \#$ & 165.50 & (161.00-169.60) & 150.50 & $(145.50-154.00)$ & 0.00 \\
\hline $\mathrm{HF}\left(\mathrm{ms}^{2}\right) \#$ & 26.30 & $(24.20-30.50)$ & 25.70 & $(22.50-28.10)$ & 0.13 \\
\hline LF (nu) \# & 99.60 & $(89.30-108.80)$ & 85.20 & $(79.50-96.90)$ & 0.00 \\
\hline HF (nu) \# & 32.00 & $(25.40-35.70)$ & 42.20 & $(34.70-47.70)$ & 0.00 \\
\hline LF/HF \# & 38.30 & $(28.30-42.90)$ & 43.70 & $(35.10-49.40)$ & 0.00 \\
\hline
\end{tabular}

Legend: $\$=$ statistical differences between genders. $\mathrm{BMI}=$ Body mass index; $\mathrm{WC}=$ Waist circumference; $\% \mathrm{BF}=\mathrm{Body}$ fat percentage; $\% \mathrm{TF}=\mathrm{Percentage}$ of trunk fat; $\mathrm{SBP}=$ Systolic blood pressure; $\mathrm{DBP}=$ Diastolic blood pressure; $\mathrm{MBP}=$ Mean blood pressure; $\mathrm{RHR}=\mathrm{Resting}$ heart rate; $\mathrm{PP}=$ pulse pressure; $\mathrm{TG}$ $=$ Triglycerides; $\mathrm{TC}=$ total cholesterol; GLU = Fasting glucose; RR = interval between consecutive heart beats; $\mathrm{SD}=$ standard deviation of $\mathrm{RR} ; \mathrm{HF}=$ high frequency spectral component; $\mathrm{LF}=$ low frequency spectral component; nu = normalized units; \# $=65$ subjects were analyzed.

Table 2 presents the comparisons of hemodynamic and metabolic variables according to RHR. It can be observed that elderly patients with an RHR $<66$ beats/min had lower DBP and GLU and higher PP compared with elderly patients with an $\mathrm{RHR} \geq 66$ beats/min. Also, according to the HRV, the individuals with RHR $<66$ had higher RRmean and SD, HFms ${ }^{2}$, HFnu, and lower LFnu and LF/HF relation.

Table 3 shows a lower prevalence of metabolic syndrome in all individuals of the sample and according to gender.

Table 4 shows the differences in GLU, TG, SBP, DBP, WC and $\mathrm{BMI}$ in the comparison between all the variable quantified in this study according to the presence of metabolic syndrome and no-metabolic syndrome eldw erly aged 80 years and over with higher values in the first group.

When the relationship between variables was verified, Spearman's correlation showed positive relationship between RHR and DBP $(\mathrm{r}=0.27 ; \mathrm{p}=0.004)$, and negative correlation between RHR with PP $(r=-0.23$; $p=0.013)$.

Table 5 shows the values of the linear regression between the hemodynamic (SBP, DBP, and PP) and metabolic (TG, TC and GLU) variables and RHR. Of note, regardless of age, sex, and $\% \mathrm{BF}, \mathrm{RHR}$ influenced the changes observed in DBP, PP and TG; however, in relation to SBP, TC and GLU the changes were not statistically significant.

\section{Discussion}

The results of this study suggest that increased levels of RHR are associated with unfavorable hemodynamic and metabolic parameters in elderly subjects aged 80 years and over.

In terms of the hemodynamic and metabolic parameters, there was no statistically significant difference between genders, except for TC which showed the highest concentrations in females. Additionally, we obtained a lower value of PP in the group with an RHR less than 66 beats/min. In general, lower HR and lower PP are associated with better prognosis (PerretGuillaume et al., 2009; Protogerou, et al., 2007); however, in this study, higher HR was associated with lower PP which was reasonable since its calculation is based on the difference between SBP and DBP. Additionally, PP is an important indicator of arterial stiffness, and the behavior of blood circulation, which is a strong predictor of cardiovascular morbidity and mortality (Protogerou, et al., 2007).

Park et al. (2010) evaluated Koreans with a mean age of 47 years and found that individuals with higher RHR had elevated SBP, DBP and increased arterial stiffness, as assessed by the ankle-brachial index. In another study conducted by Gillman et al. (1993), the authors examined the influence of RHR on hypertension and the cardiovascular disease mortality in subjects with an average age of 55 years old and concluded that subjects 
Table 2. Comparison of variables between higher and lower resting heart rate, anthropometric, metabolic, hemodynamic and heart rate variability according to gender in the elderly aged 80 years and over.

\begin{tabular}{|c|c|c|c|c|c|c|c|}
\hline Variable & $\begin{array}{c}\text { Overall } \\
\text { RHR }<66 \\
\text { beats.min-1 } \\
\mathrm{N}=63 \\
\end{array}$ & $\begin{array}{c}\text { Overall } \\
\text { RHR }>66 \\
\text { beats.min-1 } \\
\mathrm{N}=\mathbf{5 0}\end{array}$ & $\begin{array}{c}\text { RHR }<66 \text { beats. } \\
\text { min- } 1 \\
\operatorname{Men}(n=19)\end{array}$ & $\begin{array}{c}\text { RHR }>66 \text { beats. } \\
\text { min- } 1 \\
\operatorname{Men}(n=20)\end{array}$ & $\begin{array}{c}\text { RHR }<66 \text { beats. } \\
\text { min-1 } \\
\text { Women } \\
(n=44)\end{array}$ & $\begin{array}{c}\text { RHR }>66 \text { beats. } \\
\text { min-1 } \\
\text { Women } \\
(n=30)\end{array}$ & $\begin{array}{c}\text { Difference } \\
\text { Between } \\
\text { Overall } \\
\text { P } \\
\end{array}$ \\
\hline Weight (Kg) & $63.67(13.62)$ & $63.89(15.08)$ & $70.00(23.50)$ & 71.85 (19.90) & $59.30(17.40)$ & $55.30(17.00)$ & 0.93 \\
\hline BMI (kg/m2) & $26.31(4.33)$ & $25.78(3.96)$ & $26.10(8.10)$ & $26.76(6.10)$ & $26.16(4.80)$ & $25.12(6.90)$ & 0.50 \\
\hline WC (cm) & $91.18(12.49)$ & $91.37(13.31)$ & $98.50(20.50)$ & $100.25(17.80)$ & $85.50(16.60)$ & $84.80(20.90)$ & 0.94 \\
\hline$\% \mathrm{BF}$ & $38.31(9.64)$ & $35.04(9.61)$ & $34.20(6.00)$ & $28.70(11.10)$ & $42.80(10.80)$ & $39.80(16.80)$ & 0.08 \\
\hline$\% \mathrm{TF}$ & $40.89(10.57)$ & $37.44(10.52)$ & $40.80(8.70)$ & $34.60(14.00)$ & $44.30(10.70)$ & $41.30(18.90)$ & 0.09 \\
\hline SBP (mmHg) & $158.38(27.49)$ & $151.78(19.82)$ & $161.00(45.00)$ & $151.50(25.00)$ & $155.00(31.10)$ & $151.00(32.00)$ & 0.14 \\
\hline DBP $(\mathrm{mmHg})$ & $75.87(12.54)$ & $80.94(11.52)$ & $74.00(18.00)$ & $83.00(14.00)^{*}$ & $75.00(20.00)$ & $79.00(19.00)^{*}$ & 0.03 \\
\hline MBP (mmHg) & $103.37(15.61)$ & $104.55(12.58)$ & $101.33(26.30)$ & $106.17(15.00)$ & $102.00(19.30)$ & $102.67(19.70)$ & 0.66 \\
\hline PP (mmHg) & $82.51(22.52)$ & $70.84(16.60)$ & $75.00(37.00)$ & $69.00(27.00)^{*}$ & $80.00(27.00)$ & $74.00(24.00)^{*}$ & 0.00 \\
\hline TG (mg/dl) & $123.13(60.20)$ & $147.980(70.55)$ & $106.00(50.00)$ & $124.50(102.00)$ & $104.00(58.00)$ & $137.00(111.00)$ & 0.05 \\
\hline $\mathrm{TC}(\mathrm{mg} / \mathrm{dl})$ & $196.71(37.70)$ & $206.46(43.61)$ & $189.00(64.00)$ & $180.50(50)$ & $203.00(36.00)$ & $216.00(48.00)$ & 0.21 \\
\hline GLU (mg/dl) & $94.48(17.96)$ & $104.42(33.88)$ & $88.00(13.00)$ & $96.50(40)$ & $90.00(13.00)$ & $90.00(15.00)$ & 0.05 \\
\hline RR-Mean (ms) \# & $997.00(216.00)$ & $823.50(185.00)$ & $1096.00(232.00)$ & $823.50(130.00)^{*}$ & $993.00(173.00)$ & $824.00(227.00)^{*}$ & $<0.00$ \\
\hline $\mathrm{SD}(\mathrm{ms}) \#$ & $18.00(9.00)$ & $14.00(9.00)$ & $22.00(22.00)$ & $17.00(9.00)$ & $17.00(9.00)$ & $12.50(10.00)^{*}$ & 0.03 \\
\hline $\mathrm{LF}\left(\mathrm{ms}^{2}\right) \#$ & $34.83(76.35)$ & $33.94(41.86)$ & $83.58(85.98)$ & $33.94(22.60)$ & $34.78(62.50)$ & $31.66(57.40)$ & 0.28 \\
\hline $\mathrm{HF}\left(\mathrm{ms}^{2}\right) \#$ & $58.98(135.84)$ & $39.09(52.46)$ & $78.63(182.20)$ & $48.93(132.20)$ & $52.53(115.20)$ & $27.99(35.50)^{*}$ & 0.01 \\
\hline LF (nu) \# & $34.00(20.00)$ & $46.50(26.00)$ & $35.00(29.00)$ & $42.50(36.00)$ & $33.00(20.00)$ & $49.00(19.50)^{*}$ & 0.03 \\
\hline HF (nu) \# & $66.00(20.00)$ & $53.50(26.00)$ & $65.00(29.00)$ & $57.50(36.00)$ & $67.00(20.00)$ & $51.00(19.50) *$ & 0.03 \\
\hline LF/HF \# & $0.54(0.61)$ & $0.97(1.21)$ & $0.56(1.15)$ & $0.76(1.81)$ & $0.53(0.62)$ & $1.05(1.00) *$ & 0.04 \\
\hline
\end{tabular}

* = statistically significantly differences within gender; $\mathrm{IQR}=$ Interquartile range; $\mathrm{BMI}=$ Body mass index; $\mathrm{WC}=$ Waist circumference; $\% \mathrm{BF}=\mathrm{Body}$ fat percentage; $\% \mathrm{TF}=$ Percentage of trunk fat; $\mathrm{SBP}=$ Systolic blood pressure; $\mathrm{DBP}=$ Diastolic blood pressure; $\mathrm{MBP}=$ Mean blood pressure; $\mathrm{PP}=$ pulse pressure; $\mathrm{TG}=$ Triglycerides; $\mathrm{TC}=$ total cholesterol $\mathrm{GLU}=$ Fasting glucose; $\mathrm{RR}=$ interval between consecutive heart beats; $\mathrm{SD}=$ standard deviation of RR; $\mathrm{HF}=$ high frequency spectral component; $\mathrm{LF}=$ low frequency spectral component; $\mathrm{nu}=$ normalized units; $\#=\mathrm{n}$ of 65 subjects were analyzed.

Table 3. Prevalence of Metabolic Syndrome in elderly aged 80 years and over.

\begin{tabular}{|c|c|c|c|c|c|c|}
\hline \multirow[b]{2}{*}{ Risk Factor } & \multicolumn{2}{|c|}{ Overall (n=113) } & \multicolumn{2}{|c|}{ Men $(n=39)$} & \multicolumn{2}{|c|}{ Women $(n=74)$} \\
\hline & Frequency & $\%$ & Frequency & $\%$ & Frequency & $\%$ \\
\hline $\mathbf{0}$ & 10.00 & 8.80 & 6.00 & 15.40 & 4.00 & 5.40 \\
\hline 1 & 56.00 & 49.60 & 18.00 & 46.20 & 38.00 & 51.40 \\
\hline 2 & 35.00 & 31.00 & 8.00 & 20.50 & 27.00 & 36.50 \\
\hline 3 & 12.00 & 10.60 & 7.00 & 17.90 & 5.00 & 6.80 \\
\hline
\end{tabular}

with both high blood pressure and high RHR demonstrated a greater probability of death from cardiovascular diseases, including coronary artery disease, when compared with people with high blood pressure and normal or decreased RHR.

The increased blood pressure and RHR can be attributed to functional changes, such as, autonomic imbalance, resulting from an increase in the sympathetic nervous system and a reduction in the parasympathetic nervous system (Jose, \& Collison, 1970). Previous studies have shown that patients with autonomic imbalance may have a higher probability of death (Olshansky, Sabbah, Hauptman, \& Colucci, 2008; Zucker, Patel, \& Schultz, 2012). An increase in RHR results in an autonomic imbalance, which could provide increased myocardial oxygen consumption, thereby reducing the reserves of high-energy substrates, which hinders subendocardial perfusion and may result in a lowering of the atrial threshold and hence an increase in the incidence of ventricular arrhythmias (Zucker, Wang, Brandle, Schultz, $\&$ Patel, 1995). Thus, these responses may be involved in the increased mortality of those with sympathetic hyperactivity and tachycardia. In this study, an increase in DBP and RHR were found. Thus, our findings suggest a possible functional changes since we found and increase in sympathetic activity and autonomic imbalance.

Regarding to the autonomic assessment, the results show there is no difference between genders in this population, and could be observed predominance in the parasympathetic 
Table 4. Comparison between metabolic syndrome and no-metabolic syndrome elderly aged 80 years old and over.

\begin{tabular}{|c|c|c|c|}
\hline Variable & $\begin{array}{c}\text { No-MS } \\
\text { Median (IQR) } \\
\text { N=99 }\end{array}$ & $\begin{array}{c}\text { MS } \\
\text { Median (IQR) } \\
\mathrm{N}=12 \\
\end{array}$ & $p$ \\
\hline Weight (Kg) & $61.10(18.80)$ & $74.75(21.20)$ & 0.00 \\
\hline BMI (kg/m²) & $25.77(5.50)$ & $30.30(5.40)$ & $<0.00$ \\
\hline WC (cm) & $89.00(17.40)$ & $105.80(14.20)$ & $<0.00$ \\
\hline$\% \mathrm{BF}$ & $36.20(13.00)$ & $39.90(20.30)$ & 0.44 \\
\hline \%TF & $41.00(12.70)$ & $45.20(15.60)$ & 0.10 \\
\hline SBP (mmHg) & $152.00(31.00)$ & $165.00(26.00)$ & 0.03 \\
\hline DBP (mmHg) & $76.00(20.00)$ & $86.00(13.00)$ & 0.01 \\
\hline PP (mmHg) & $74.00(23.00)$ & $74.50(25.00)$ & 0.49 \\
\hline TG (mg/dl) & $103.00(64.00)$ & $212.00(68.00)$ & $<0.00$ \\
\hline TC (mg/dl) & $201.00(47.00)$ & $214.00(63.00)$ & 0.17 \\
\hline GLU (mg/dl) & $89.00(12.00)$ & $129.50(51.00)$ & $<0.00$ \\
\hline HR (bmp) & $63.00(14.00)$ & $70.50(18.00)$ & 0.07 \\
\hline RR-Mean (ms) \# & $920.00(221.00)$ & $913.00(353.00)$ & 0.40 \\
\hline SD \# & $17.00(9.00)$ & $19.50(27.00)$ & 0.31 \\
\hline $\mathbf{L F}\left(\mathbf{m s}^{2}\right) \#$ & $33.74(59.36)$ & $66.14(54.79)$ & 0.36 \\
\hline HF $\left(\mathbf{m s}^{2}\right) \#$ & $45.62(57.23)$ & $43.59(112.52)$ & 0.44 \\
\hline $\mathbf{L F}(\mathbf{n u}) \#$ & $41.00(21.00)$ & $57.00(27.00)$ & 0.83 \\
\hline HF (nu) \# & $59.00(21.00)$ & $43.00(27.00)$ & 0.83 \\
\hline LF/HF \# & $0.77(0.72)$ & $1.59(3.28)$ & 0.89 \\
\hline
\end{tabular}

$\mathrm{MS}=$ metabolic syndrome; $\mathrm{IQR}=$ Interquartile range $\mathrm{BMI}=$ Body mass index $; \mathrm{WC}=$ Waist circumference; $\% \mathrm{BF}=$ Body fat percentage; $\% \mathrm{TF}=\mathrm{Percentage}$ of trunk fat; $\mathrm{SBP}=$ Systolic blood pressure; $\mathrm{DBP}=$ Diastolic blood pressure; $\mathrm{MBP}=$ Mean blood pressure; $\mathrm{PP}=$ pulse pressure; $\mathrm{TG}=$ Triglycerides; $\mathrm{TC}=$ total cholesterol; GLU = Fasting glucose; RR = interval between consecutive heart beats; $\mathrm{SD}$ = standard deviation of RR; HF = high frequency spectral component; $\mathrm{LF}=$ low frequency spectral component; $\mathrm{nu}=$ normalized units; $\#=\mathrm{n}$ of 65 subjects were analyzed.

Table 5. Linear regression between the resting heart rate, systolic and diastolic blood pressure, pulse pressure and blood glucose after adjusting for age, gender and body fat percentage in the elderly aged 80 years old and over.

\begin{tabular}{cccccccccccc}
\hline & \multicolumn{3}{c}{ RHR- adjusted for age } & \multicolumn{3}{c}{ RHR- adjusted for age and gender } & \multicolumn{3}{c}{$\begin{array}{c}\text { RHR- adjusted for age. gender and } \\
\text { \%BF }\end{array}$} \\
\hline & $\boldsymbol{B}$ & $\boldsymbol{p}$ & $\mathbf{C I - 9 5 \%}$ & $\boldsymbol{\beta}$ & $\boldsymbol{p}$ & $\mathbf{C I - 9 5 \%}$ & $\boldsymbol{\beta}$ & $\boldsymbol{p}$ & $\mathbf{C I - 9 5 \%}$ \\
$\mathbf{S B P}(\mathbf{m m H g})$ & -0.03 & 0.50 & $(-0.12 ; 0.06)$ & -0.02 & 0.57 & $(-0.12 ; 0.06)$ & -0.02 & 0.68 & $(-0.11 ; 0.07)$ \\
DBP (mmHg) & 0.27 & 0.00 & $(0.09 ; 0.44)$ & 0.27 & 0.00 & $(0.09 ; 0.44)$ & 0.26 & 0.00 & $(0.09 ; 0.43)$ \\
PP (mmHg) & -0.13 & 0.01 & $(-0.24 ;-0.03)$ & -0.13 & 0.02 & $(-0.23 ;-0.02)$ & -0.12 & 0.03 & $(-0.22 ;-0.01)$ \\
TG (mg/dl) & 0.03 & 0.08 & $(-0.00 ; 0.06)$ & 0.03 & 0.07 & $(-0.00 ; 0.06)$ & 0.04 & 0.03 & $(0.00 ; 0.07)$ \\
TC (mg/dl) & 0.04 & 0.29 & $(-0.03 ; 0.08)$ & 0.04 & 0.16 & $(-0.02 ; 0.10)$ & 0.05 & 0.10 & $(-0.01 ; 0.10)$ \\
GLU (mg/d) & 0.04 & 0.38 & $(-0.05 ; 0.12)$ & 0.03 & 0.42 & $(-0.05 ; 0.12)$ & 0.04 & 0.33 & $(-0.04 ; 0.12)$ \\
\hline
\end{tabular}

$\overline{\mathrm{RHR}}=$ resting heart hate; $\mathrm{SBP}=$ Systolic blood pressure; $\mathrm{DBP}=$ Diastolic blood pressure; $\mathrm{PP}=$ pulse pressure; $\mathrm{TG}=\mathrm{Triglycerides} ; \mathrm{TC}=$ total cholesterol; $\mathrm{BF}=$ percentage of body fat.

response at rest for both groups. Similarly, no differences were observed when the groups with and without metabolic syndrome were evaluated. However, when the groups were compared between the differences in the RHR values, it can be observed higher parasympathetic modulation by the increase in the HF values in $\mathrm{ms}^{2}$ and $\mathrm{nu}$, better balance in the relation $\mathrm{LF} / \mathrm{HF}$ and low value to the index that represent the predominance of sympathetic branch - LF (nu) (Tarvainen, Niskanen, Lipponen, RantaAho, \& Karjalainen, 2009; Vanderlei, Pastre, Hoshi, Carvalho, \& Godoy, 2009). These findings reinforce the RHR results.

Regarding the metabolic parameters, the present study showed that elderly subjects with higher RHR values have altered GLU and a trend in the TG compared to those with lower RHR, the changes in TG being independent of age, sex and \%BF as shown in Table 3. However, after adjustment, the influence on the GLU ceased to exist. Regarding the values of TG between the two groups, these values are within normal limit. Kowalski et al. (2012) in a recent study conducted with subjects with a average age of 57.4 years found that an RHR of $\geq 72.5$ beats/ $\mathrm{min}$ is an independent risk factor for disorders in the absorption of carbohydrates. These same authors also added that subjects with carbohydrate absorption disorders demonstrated an RHR significantly greater than the control group. In our study we found that a $R H R \geq 66$ beats/min is related with unfavorable 
hemodynamic and metabolic parameters in elderly subjects aged 80 years and over. Thus, we suggest for future studies investigate lower values of RHR as independent risk factors.

In relation to the anthropometric parameters, the women had higher $\% \mathrm{BF}$ and $\mathrm{TF}$, but a smaller WC compared with the men; however, no statistical difference regarding RHR. It is known that weight gain, BF, particularly in the trunk region (Donato, Fuchs, Oppermann, Bastos, \& Spritzer, 2006), and a sedentary lifestyle are conditions that impair the quality of life during the aging process (Ford, Li, Zhao, Pearson, Tsai, \& Churilla, 2010) since they are associated with the development of morbidities such as diabetes mellitus, hypertension, dyslipidemia and metabolic syndrome (Gruen, Hao, Piston, \& Hasty, 2007). So, the findings of this study suggest that women could present higher impairment arising from the aging process.

Despite the importance of the findings presented here, some limitations need to be mentioned such as the characteristics of the individuals assessed regarding the risk factors and cardiovascular diseases and medication not being evaluated. However, they were described according with risk factors for the development of cardiovascular diseases and the volunteers were requested to suspend medications for a period of 12 hours prior to the autonomic evaluation. This is important because Menown et al. (2013) indicated that RHR is associated with an increment in the risk for all-cause morbidity and mortality, including cardiovascular mortality, in populations with or without risk factors or cardiovascular disease. And in another diseases, that have decrease of heart rate variability as with age, this measurement is independent of the use of some medications (Bédard, Marquis, Poirier, \& Provencher, 2010). A strong aspect of the study which stands out is the randomization of the sampling process, which ensured that each elderly subject contained the same chance of being drawn. The sample was composed only of elderly people considered long-lived ( $>80$ years), which is another highlight of the study, since there are few studies involving RHR and anthropometric, metabolic and hemodynamic parameters in this population. Finally, it is suggested that longitudinal studies should be performed to verify the influence of different forms of intervention on RHR and the hemodynamic, metabolic and anthropometric parameters in this population.

\section{Conclusion}

A positive relationship between RHR and some metabolic and hemodynamic parameters and elderly aged 80 years and over was found. Subjects with 80 years old and over who present RHR $\geq 66$ have higher DBP and lower PP and heart rate variability compared with the elderly with RHR $<66$.

\section{References}

Bédard, M.E., Marquis, K., Poirier, P., \& Provencher, S. (2010). Reduced heart rate variability in patients with chronic obstructive pulmonary disease independent of anticholinergic or $\beta$-agonist medications. COPD: Journal of Chronic Obstructive Pulmonary Disease, 7, 391-397. doi: 10.3109/15412555.2010.528083.

Benetos, A., Rudnichi, A., Thomas, F., Safar, M., \& Guize, L. (1999). Influence of heart rate on mortality in a French population: role of age, gender, and blood pressure. Hypertension, 33, 44-52. doi: 10.1161/01.HYP.33.1.44.

Coleman, A., Freeman, P., Steel, S., \& Shennan, A. (2005). Validation of the Omron MX3 Plus oscillometric blood pressure monitoring device according to the European Society of Hypertension international protocol. Blood Pressure Monitoring, 10, 165-168. doi: 00126097-200506000-00009.

Cooney, M. T., Vartiainen, E., Laatikainen, T., Juolevi, A., Dudina, A., \& Graham, I.M. (2010). Elevated resting heart rate is an independent risk factor for cardiovascular disease in healthy men and women. American Heart Journal, 159, 612-619. doi: 10.1016/j. ahj.2009.12.029.

Donato, G. B., Fuchs, S. C., Oppermann, K., Bastos, C., \& Spritzer, P. M. (2006). Association between menopause status and central adiposity measured at different cutoffs of waist circumference and waist-to-hip ratio. Menopause, 13, 280-285. doi: 00042192-200613020-00018.

Freitas, I.F, Jr. (2009). Medidas: estatura, peso, comprimento dos segmentos. Padronização de técnicas antropométricas. Presidente Prudente (SP): Cultura Acadêmica, 23-5.

Freitas, I.F, Jr., Monteiro, P.A., Silveira, L.S., Cayres, S.U., Antunes, B.M., Bastos, K.N., ... \& Fernandes, R.A. (2012). Resting heart rate as a predictor of metabolic dysfunctions in obese children and adolescents. BMC pediatrics, 12(1), 5. doi: 10.1186/1471-2431-12-5.

Ford, E.S., Li, C., Zhao, G., Pearson, W.S., Tsai, J., \& Churilla, J.R. (2010). Sedentary behavior, physical activity, and concentrations of insulin among US adults. Metabolism, 59, 1268-1275. doi: 10.1016/j.metabol.2009.11.020.

Gillman, M.W., Kannel, W.B., Belanger, A., \& D’Agostino, R.B. (1993). Influence of heart rate on mortality among persons with hypertension: the Framingham Study. American Heart Journal, $125,1148-1154$.

Girotto, E., Andrade, S.M., Cabrera. M.A.S., \& Ridão, E.G. (2009). Prevalência de fatores de risco para doenças cardiovasculares em hipertensos cadastrados em unidade de saúde da família. Acta Scientiarum Health Sciences, 31, 77-82. doi: 10.4025/actascihealthsci.v31i1.4492.

Gruen, M.L., Hao, M., Piston, D.W., \& Hasty, A.H. (2007). Leptin requires canonical migratory signaling pathways for induction of monocyte and macrophage chemotaxis. American Journal Physiology-Cell Physiology, 293, 1481-1488. doi: 10.1152/ ajpcell.00062.2007

Hashmi, A., Ibrahim-Zada, I., Rhee, P., Aziz, H., Fain, M.J., Friese, R.S., \& Joseph, B. (2014). Predictors of mortality in geriatric trauma patients: a systematic review and meta-analysis. Journal of Trauma and Acute Care Surgery, 76(3), 894-901. doi: 10.1097/ TA.0b013e3182ab0763.

Human, R.P., \& Jones, G.A. (2004). Evaluation of swab transport systems against a published standard. Journal of Clinical Pathology, 57, 762-773. doi:10.1136/jcp.2004.016725.

Jose, A.D., \& Collison, D. (1970). The normal range and determinants of the intrinsic heart rate in man. Cardiovasc Research, 4, 160-167. doi: http://dx.doi.org/10.1093/cvr/4.2.160. 
Kochiadakis, G.E., Kanoupakis, E.M., Rombola, A.T., Igoumenidis, N.E., Chlouverakis, G.I., \& Vardas, P.E. (1998). Reproducibility of tilt table testing in patients with vasovagal syncope and its relation to variations in autonomic nervous system activity. Pacing and clinical electrophysiology,21(5), 1069-1076.

Kowalski, J., Brylik, A., Irzmański, R., Pawlicki, L., Ciećwierz, J., Jarzabek, K., \& Barylski, M. (2012). (Resting heart rate in subjects with carbohydrate disorders). Polski merkuriusz lekarski: organ Polskiego Towarzystwa Lekarskiego, 32(188), 93-97.

Lauria, A.A., Santos, T.M., Amorim, P.R.S., Marques, F.A.D., Lima, J.R.P. Prediction of 8 baseline heart rate of individuals with different levels of habitual physical activity. 9 Rev Bras Med Esporte. 2013;19(1).

Lean, M.E., Han, T.S., \& Morrison, C.E. (1995). Waist circumference as a measure for indicating need for weight management. British Medical Journal, 311, 158-161. doi: http://dx.doi.org/10.1136/ bmj.311.6998.158

Menown, I., Davies, S., Gupta, S., Kalra, P.R., Lang, C.C., Morley, C., \& Padmanabhan, S. (2013). Resting heart rate and outcomes in patients with cardiovascular disease: where do we currently stand? Cardiovascular therapeutics, 31(4), 215-223. doi: 10.1111/j.1755-5922.2012.00321.x.

Nogueira, M.C., Ribeiro, L.C., \& Cruz, O.G. (2009). Social inequalities in premature cardiovascular mortality in a medium-size Brazilian city. Cadernos de Saúde Pública, 25, 2321-2332.

Olshansky, B., Sabbah, H.N., Hauptman, P.J., \& Colucci, W.S. (2008). Parasympathetic nervous system and heart failure: pathophysiology and potential implications for therapy. Circulation, 118, 863-871. doi: 10.1161/CIRCULATIONAHA.107.760405

Palatini, P., Benetos, A., Grassi, G., Julius, S., Kjeldsen, S.E., Mancia, G., ... \& Zanchetti, A. (2006). European Society of Hypertension Identification and management of the hypertensive patient with elevated heart rate: statement of a European Society of Hypertension Consensus Meeting. Journal Hypertension, 24(4), 603-610. doi: 00004872-200604000-00001.

Palatini, P. (2009). Elevated Heart Rate: A "New" Cardiovascular Risk Factor? Progress in Cardiovascular Diseases, 52, 1-5. doi:10.1016/j.pcad.2009.06.001

Park, B-J., Lee, H.R., Shim, J.Y., Lee, J.H., Jung, D.H., \& Lee, Y.J. (2010). Association between resting heart rate and arterial stiffness in Korean adults. Archives of Cardiovascular Disease, 103, 246252. doi: 10.1016/j.acvd.2010.03.004

Pickering, T.G., Hall, J.E., Appel, L.J., Falkner, B.E., Graves, J., Hill, M.N., ... \& Roccella, E.J. (2005). Subcommittee of Professional and Public Education of the American Heart Association Council on High Blood Pressure Research. Recommendations for blood pressure measurement in humans and experimental animals: Part 1: blood pressure measurement in humans: a statement for professionals from the Subcommittee of Professional and Public Education of the American Heart Association Council on High Blood Pressure Research. Hypertension, 45(1), 142-161.

Perret-Guillaume C1, Joly L, Benetos A. Heart rate as a risk factor for cardiovascular disease. American Heart Association Council on High Blood Pressure Research. Prog Cardiovasc Dis. 2009 Jul-Aug;52(1):6-10. doi: 10.1016/j.pcad.2009.05.003.

Protogerou, A.D., Papaioannou, T.G., Blacher, J., Papamichael, C.M., Lekakis, J.P., \& Safar, M.E. (2007). Central blood pressures: do we need them in the management of cardiovascular disease? Is it a feasible therapeutic target? Journal Hypertension, 25, 265-272. doi: 00004872-200702000-00002.

Recommendations for blood pressure measurement in humans and experimental animals: Part 1: blood pressure measurement in humans: a statement for professionals from the Subcommittee of Professional and Public Education of the American Heart Association Council on High Blood Pressure Research. Hypertension, 45(1), 142-161.

Rossi, F.E., Ricci-Vitor, A. ., Sabino, J. ., Vanderlei, L., \& Freitas, I. F., Jr. (2014). Autonomic modulation and its relation with body composition in swimmers. The Journal of Strength \& Conditioning Research, 28(7), 2047-2053. doi: 10.1519/JSC.0000000000000344.

Santana, J.S., Franco Filho, J.C.S., Neto, S., Melo, E.V.D., Santana, N.O.D., Barreto, A.T.F., ... \& Oliveira, J.L.M. (2013). Prognostic value of chronotropic incompetence in elderly patients undergoing exercise echocardiography. Arquivos brasileiros de cardiologia, 100(5), 429-436.

Vanderlei, L.C.M., Pastre, C.M., Hoshi, R.A., Carvalho, T.D.D., \& Godoy, M.F.D. (2009). Noções básicas de variabilidade da frequência cardíaca e sua aplicabilidade clínica. Rev Bras Cir Cardiovasc, 24(2), 205-17.

Tarvainen, M.P., Niskanen, J.P., Lipponen, J.A., Ranta-Aho, P.O., \& Karjalainen, P.A. (2009). Kubios HRV-a software for advanced heart rate variability analysis. In 4th European Conference of the International Federation for Medical and Biological Engineering (pp. 1022-1025). Springer Berlin Heidelberg.

Zucker, I.H., Wang, W., Brandle, M., Schultz, H.D., \& Patel, K.P. (1995). Neural regulation of sympathetic nerve activity in heart failure. Progress in Cardiovascular Diseases, 37, 397-414. doi: 10.5935/abc.20130091.

Zucker, I.H., Patel, K.P., \& Schultz, H.D. (2012). Neurohumoral stimulation. Heart Fail Clinical, 8, 87-99. doi: 10.1016/j.hfc.2011.08.007.

WHO. World Health Organization Consequences of overweight and obesity on the health of adults and children. In: WHO. Obesity Preventing and Controlling Global Epidemic. 1. Ed. Sao Paulo: ROCA, 2004.

\section{Author's note}

Fabrício E. Rossi and Vanessa R. dos Santos are affiliated with the Institute of Bioscience, São Paulo State University, Rio Claro, São Paulo, Brazil.

Ana Laura Ricci-Vitor is affiliated with the Department of Physiotherapy, University Federal of São Paulo, São Paulo, SP, Brazil. Igor C. Gomes is affiliated with the Departament of Epidemiology, University of São Paulo, São Paulo, SP, Brazil.

João Paulo J. Sabino and Luiz Guilherme S. Branco are affiliated with the Department of Physiology, Dental School of Ribeirão Preto, University of São Paulo, Ribeirão Preto, Brazil.

Luiz Carlos M. Vanderlei is affiliated with the Department of Physiotherapy, São Paulo State University, Presidente Prudente, São Paulo, Brazil.

Diego G. D. Christofaro and Ismael F. Freitas Junior are affiliated with the Department of Physical Education, São Paulo State University, Presidente Prudente, São Paulo, Brazil. 


\section{Corresponding author}

Fabrício Eduardo Rossi

Department of Physical Education, University, Estadual Paulista, Presidente Prudente, São Paulo, Brazil

Rua Roberto Simonsen, no 305 - Centro Educacional, Presidente Prudente, CEP 19060-900, São Paulo, Brasil.

Email: rossifabricio@yahoo.com.br

Manuscript received on June 16, 2015

Manuscript accepted on December 12, 2015

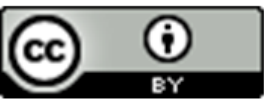

Motriz. The Journal of Physical Education. UNESP. Rio Claro, SP, Brazil - eISSN: 1980-6574 - under a license Creative Commons - Version 3.0 